\title{
PVT Property Measurements for Ethyl Propionate, Ethyl Butyrate, and Ethyl Pentanoate Esters from (298 to 393) $\mathrm{K}$ and up to $35 \mathrm{MPa}^{\dagger}$
}

\author{
Henrique F. Costa, Ramesh L. Gardas, Irudayaraj Johnson, Isabel M. A. Fonseca, and Abel G. M. Ferreira* \\ Departamento de Engenharia Química, Universidade de Coimbra, Pólo II, Rua Sílvio Lima, 3030-790 Coimbra, Portugal
}

\begin{abstract}
The results of $P V T$ measurements of the liquid phase within the temperature range (298 to 393) K and up to $35 \mathrm{MPa}$ are presented for some aliphatic esters. Measurements were made by means of a vibrating tube densimeter, model DMA 512P from Anton Parr. The calibration of the densimeter was performed with water and $n$-heptane as reference fluids. The experimental $P V T$ data have been correlated by a Tait equation. This equation gives good results when used to predict the density of the esters using the method proposed by Thomson et al. Isothermal compressibilities, isobaric expansivities, thermal pressure coefficients, and changes in the isobaric heat capacity have been calculated from the Tait equation.
\end{abstract}

\section{Introduction}

Thermophysical properties of aliphatic esters are particularly important in the pharmaceutical, food, and flavor industries. In our research group, several studies of density, viscosity, and interfacial tensions have been made for several esters at room temperature and atmospheric pressure ${ }^{1-5}$ including the ethyl propionate and the ethyl butyrate. The densities of these esters have been recently investigated by other authors ${ }^{6-8}$ at atmospheric pressure. Detailed research investigations of these properties for pure esters, in large temperature and pressure ranges, are scarce in the literature. Recently, we have extended the pressure domain of density measurements, and we have determined reliable density data for some alkyl acetates (ethyl, propyl, $n$-butyl, and $n$-pentyl acetates) in the temperature range (298.15 to 393.15 ) $\mathrm{K}$ and up to $35 \mathrm{MPa}^{1}$ In this study, new reliable density data for ethyl propionate, ethyl butyrate, and ethyl pentanoate from (298 to 393) $\mathrm{K}$ and up to $35 \mathrm{MPa}$ are presented. For ethyl pentanoate, the reported data are very limited and are reported only at atmospheric pressure. ${ }^{10,11}$ As far as we know, the available literature density data for ethyl propionate and ethyl butyrate in the high-pressure domain are the measurements due to Malhotra and Woolf ${ }^{9}$ in the temperature range (278 to 338 ) $\mathrm{K}$ and up to $380 \mathrm{MPa}$. In this work, we have extended the temperature up to $393 \mathrm{~K}$.

The density data obtained in this work have been correlated with the Tait equation using as a reference the saturated liquid equilibrium curve. From this equation, isothermal compressibilities, isobaric expansivities, thermal coefficients, and changes in isobaric heat capacity have been calculated and reported as Supporting Information.

The method of Thomson et al. ${ }^{12}$ was applied to the prediction of the density in the pressure and temperature ranges considered since it is a model based on the Tait equation.

\section{Experimental Section}

Materials. All the materials used are proanalysis grade. Tridistilled water was used. $\mathrm{N}$-Heptane was from Laboratory-

\footnotetext{
* To whom correspondence should be addressed. E-mail: abel@ eq.uc.pt. Phone: +351-239798729. Fax: +351-239798703.

'Part of the special issue "Robin H. Stokes Festschrift".
}

Scan with a stated purity higher than 99 (mass \%). The esters (ethyl propionate, butyrate, and pentanoate) were obtained from Acros Organics with purities of $>99.0$ mass \% and have been used without further purification. The density data at different temperatures and at atmospheric pressure obtained in this work are compared with literature values in Table 1 .

Experimental Procedure. Experimental densities were measured using an Anton Paar DMA 60 digital vibrating tube densimeter, with a DMA 512P measuring cell in the temperature range (293.15 to 393.15$) \mathrm{K}$ and pressure range (0.10 to 35.00$)$ $\mathrm{MPa}$. Figure 1 shows the installation of the DMA 512P cell and the peripheral equipment used. The temperature in the vibrating tube cell was measured with a platinum resistance probe which has a temperature uncertainty of $\pm 0.01 \mathrm{~K}$ coupled with a GW Instek Dual Display Digital Multimeter GDM-845. A Julabo P-5 thermostatic bath with silicone oil as circulating fluid was used in the thermostat circuit of the measuring cell which was held constant to $\pm 0.01 \mathrm{~K}$.

The required pressure was generated and controlled with a Pressure Generator model 50-6-15, High Pressure Equipment Co., using acetone as the hydraulic fluid. The diameter of the metallic tube is $1.59 \cdot 10^{-3} \mathrm{~m}$, and the buffer is more than $1 \mathrm{~m}$ in length which guarantees the inexistence of diffusion of the hydraulic liquid in the liquid contained in the cell of the densimeter. Pressures were measured with a pressure transducer (Wika Transmitter S-10, WIKA Alexander Wiegand GmbH \& Co.) with a maximum uncertainty of $\pm 0.03 \mathrm{MPa}$. An NI PCI6220 data acquisition board (DAQ) from National Instruments (NI) was used for the real time registration of values of period, temperature, and pressure. For this task, a Labview application was developed. Modules of temperature (NI SCC-FT01) and pressure (NI SCC-CI20) were installed into a NI SC-2345 carrier and connected to the DAQ board.

The calibration of the vibrating tube densimeter was described in a previous work. ${ }^{1}$ The equation proposed by Niesen ${ }^{14}$ which has a solid theoretical basis as discussed by Holcom and Outcalt $^{15}$ was used for that purpose. Using PVT data of water and $n$-heptane as reference fluids, the standard deviation of the fitted calibration curve was $1 \mathrm{~kg} \cdot \mathrm{m}^{-3}$. As shown in our previous work, ${ }^{1}$ the influence of the viscosity on the density is insignificant. 
Table 1. Densities of Pure Esters at Different Temperatures and at Atmospheric Pressure, Obtained in this Work and from the Literature

\begin{tabular}{|c|c|c|c|}
\hline \multirow[b]{2}{*}{ ester } & \multirow[b]{2}{*}{$T / \mathrm{K}$} & \multicolumn{2}{|r|}{$\rho / \mathrm{kg} \cdot \mathrm{m}^{-3}$} \\
\hline & & this work & literature \\
\hline \multirow[t]{14}{*}{ ethyl propionate } & 298.15 & 884.3 & $884.359^{a} ; 884.16^{b} ; 884.0^{c}$ \\
\hline & 303.15 & 878.5 & $878.87^{d} ; 879.14^{e} ; 879.03^{b}$ \\
\hline & 308.15 & 872.7 & $873.33^{e}$ \\
\hline & 313.15 & 866.8 & $867.094^{a}$ \\
\hline & 318.15 & 860.9 & $861.60^{e}$ \\
\hline & 323.15 & 854.9 & $855.456^{a}$ \\
\hline & 328.15 & 849.2 & $849.85^{e}$ \\
\hline & 333.15 & 843.1 & $843.96^{e}$ \\
\hline & 338.15 & 836.9 & $837.671^{a}$ \\
\hline & 343.15 & 831.1 & \\
\hline & 348.15 & 824.9 & \\
\hline & 353.15 & 818.7 & \\
\hline & 363.15 & 803.5 & \\
\hline & 373.15 & 790.9 & \\
\hline \multirow{16}{*}{ ethyl butyrate } & 298.15 & 873.3 & $873.668^{a} ; 873.47^{f} ; 873.94^{c}, 874.32^{e}$ \\
\hline & 303.15 & 868.1 & $868.21^{g} ; 868.83^{e}$ \\
\hline & 308.15 & 862.6 & $863.40^{e}$ \\
\hline & 313.15 & 857.3 & $857.765^{a} ; 857.98^{e}$ \\
\hline & 318.15 & 851.9 & $852.46^{e}$ \\
\hline & 323.15 & 846.7 & $847.031^{a} ; 847.03^{e}$ \\
\hline & 328.15 & 841.4 & $841.54^{e}$ \\
\hline & 333.15 & 835.8 & \\
\hline & 338.15 & 830.3 & $830.781^{a}$ \\
\hline & 343.15 & 824.8 & \\
\hline & 348.15 & 819.1 & \\
\hline & 353.15 & 813.5 & \\
\hline & 363.15 & 799.9 & \\
\hline & 373.15 & 788.5 & \\
\hline & 383.15 & 776.9 & \\
\hline & 393.15 & 765.1 & \\
\hline \multirow[t]{16}{*}{ ethyl pentanoate } & 298.15 & 870.7 & $869.39^{h}$ \\
\hline & 303.15 & 865.5 & $866.90^{i}$ \\
\hline & 308.15 & 860.3 & \\
\hline & 313.15 & 855.0 & $856.81^{i}$ \\
\hline & 318.15 & 849.8 & \\
\hline & 323.15 & 844.4 & \\
\hline & 328.15 & 839.1 & \\
\hline & 333.15 & 833.7 & \\
\hline & 338.15 & 828.4 & \\
\hline & 343.15 & 823.0 & \\
\hline & 348.15 & 817.7 & \\
\hline & 353.15 & 812.2 & \\
\hline & 363.15 & 801.2 & \\
\hline & 373.15 & 790.7 & \\
\hline & 383.15 & 779.9 & \\
\hline & 393.15 & 769.0 & \\
\hline
\end{tabular}

${ }^{a} \operatorname{Ref} 9 .{ }^{b} \operatorname{Ref} 6 .{ }^{c} \operatorname{Ref} 13 .{ }^{d} \operatorname{Ref} 2 .{ }^{e} \operatorname{Ref} 7 .{ }^{f} \operatorname{Ref} 8 .{ }^{g} \operatorname{Ref} 4 .{ }^{h} \operatorname{Ref} 10$. ${ }^{i} \operatorname{Ref} 11$.

\section{Results and Discussion}

Density measurements were carried out in wide ranges of temperatures, (298 to 393) K, and pressures, (0.1 to 35) MPa. Particular attention was given to the subcritical data, and therefore we have measured the density in the above-mentioned temperature domain for several subcritical pressure values. The experimental data for ethyl propionate, ethyl butyrate, and ethyl pentanoate are reported in Tables 2 to 4 . In Figure 2, we represent the isotherms of the density, $\rho$, for ethyl propionate. The expected behavior with temperature and pressure is found. The densities of the esters decrease with the increase of the alkanoate chain length, and this effect is more important at low temperature. This behavior was also observed in our previous reported data for alkyl acetates ${ }^{1}$ and was discussed on the basis that addition of $-\mathrm{CH}_{2}-$ groups disrupts the local configurational order of the $-\mathrm{COO}-$ group causing a lower molecular packing efficiency which leads to the decrease in the density. ${ }^{16}$

The density data due to Malhotra and Woolf ${ }^{9}$ for ethyl propionate and ethyl butyrate at temperatures of $(298.14,313.14$,
323.14, and 338.13) $\mathrm{K}$ have been compared with our own measurements at the same temperatures and pressures. The results of comparison are shown in Figure 3. The average absolute deviation, AAD, defined as

$$
\operatorname{AAD}(\%)=\frac{\sum_{i=1}^{N_{\mathrm{p}}} \mathrm{l}\left(\rho_{\text {exptl }}-\rho_{\text {lit. }}\right) / \rho_{\text {lit. }} \mathrm{I}_{i}}{N_{\mathrm{p}}}
$$

is $0.2 \%$ for both substances. In eq $1, \rho_{\text {exptl }}$ and $\rho_{\text {lit. }}$ are, respectively, the experimental density data from this work and the experimental values found by Malhotra and Woolf ${ }^{9}$ for the same temperature and pressure, and $N_{\mathrm{p}}$ represents the number of points.

The Tait equation

$$
\rho=\frac{\rho^{\text {ref }}}{\left\{1-C \ln \frac{(B+P)}{\left(B+P^{\text {ref }}\right)}\right\}}
$$

was fitted to the experimental density data in the ranges of pressures and of temperatures mentioned above. As discussed in a previous work, ${ }^{1}$ the saturated liquid state $(\sigma)$ was selected here as the reference state which means $\rho^{\text {ref }}=\rho^{\ell, \sigma}$ and $P^{\text {ref }}=$ $P^{\sigma}$. The vapor pressure $\left(P^{\sigma}\right)$ of the ethyl propionate and ethyl butyrate was obtained from the Wagner equation

$$
\begin{aligned}
\ln \left(P^{\sigma} / \mathrm{kPa}\right)=\ln \left(P_{\mathrm{c}} / \mathrm{kPa}\right)+\left(T_{\mathrm{c}} / T\right)\left(n_{1} \tau+\right. & \\
& \left.n_{2} \tau^{1.5}+n_{3} \tau^{3}+n_{4} \tau^{6}\right)
\end{aligned}
$$

where $\tau=1-T_{\mathrm{r}}$. The critical constants $\left(T_{\mathrm{c}}, P_{\mathrm{c}}\right)$ and the parameters $n_{\mathrm{i}}$ are listed in Table 5. For ethyl pentanoate we have used the Antoine equation

$$
\ln \left(P^{\sigma} / \mathrm{kPa}\right)=n_{1}-n_{2} /\left[(T / \mathrm{K})+n_{3}\right]
$$

The values of the saturated liquid density for a given temperature were obtained from values of density data measured at pressures lower than the critical, using eqs 3 and 4 as explained before. ${ }^{1}$

The density data of the saturated liquid $\left(\rho^{\prime, \sigma}\right)$ are reported in Table 6. The Rackett equation, modified by Spencer and Danner $^{21}$

$$
\rho^{\ell, \sigma}=\left\{\frac{M P_{\mathrm{c}}}{R T_{\mathrm{c}}}\right\} \frac{1}{Z_{\mathrm{RA}}^{\left[1+\left(1-T_{\mathrm{r}}\right)^{2 /]}\right]}}
$$

was fitted to the density data of the saturated liquid in the range (298.15 to 393.15) K. The values of the fitted parameter $Z_{\mathrm{RA}}$ and the associated standard deviation of the fit, $\sigma$, defined as

$$
\sigma=\left[\sum_{i=1}^{N_{\mathrm{p}}}\left(\rho_{\text {calcd }}^{\ell \sigma}-\rho_{\text {expt }}^{\ell, \sigma}\right)_{i}^{2} /\left(N_{\mathrm{p}}-k\right)\right]^{1 / 2}
$$

where $\rho_{\text {calcd }}^{\zeta \sigma}$ and $\rho_{\text {exptl }}^{\zeta \sigma}$ are, respectively, the density data from eq 5 determined as described above and $k$ is the number of adjusted parameters $(k=1)$, are listed in Table 7. In the same table, values of density at the critical point $\left(\rho_{c}\right)$ obtained from eq 5 are compared with literature ones. The accordance is good. The calculated values of the saturated liquid density from eq 5 are represented in Figure 4, and our values of $\rho_{\text {exptt }}^{\not \sigma}$ are compared with those from the literature for ethyl propionate. As for the other alkyl acetates studied, ${ }^{1}$ the agreement is good and the saturation curves can be well predicted in all the liquid + gas equilibrium ranges using eq 5 fitted to density data in a very narrow range of temperatures. 
Table 2. Experimental Density, $\rho$, Data for Ethyl Propionate as a Function of Temperature, $T$, and Pressure, $P$

\begin{tabular}{|c|c|c|c|c|c|c|c|c|c|c|c|c|}
\hline \multirow[b]{2}{*}{$T / \mathrm{K}$} & \multicolumn{12}{|c|}{$\rho / \mathrm{kg} \cdot \mathrm{m}^{-3}$ at $P / \mathrm{MPa}$} \\
\hline & 0.10 & 1.00 & 2.00 & 3.00 & 3.34 & 5.00 & 10.00 & 15.00 & 20.00 & 25.00 & 30.00 & 35.00 \\
\hline 298.15 & 884.3 & 884.8 & 885.7 & 886.6 & 886.9 & 888.7 & 892.9 & 896.9 & 900.7 & 904.4 & 908.9 & 913.6 \\
\hline 303.15 & 878.5 & 879.0 & 880.0 & 880.9 & 881.2 & 883.0 & 887.4 & 891.6 & 895.6 & 899.4 & 904.0 & 908.9 \\
\hline 308.15 & 872.7 & 873.2 & 874.2 & 875.2 & 875.5 & 877.4 & 882.0 & 886.3 & 890.4 & 894.3 & 899.2 & 904.2 \\
\hline 313.15 & 866.8 & 867.4 & 868.4 & 869.4 & 869.8 & 871.7 & 876.5 & 880.9 & 885.1 & 889.3 & 894.4 & 899.5 \\
\hline 318.15 & 860.9 & 861.5 & 862.6 & 863.7 & 864.1 & 866.1 & 871.0 & 875.6 & 880.0 & 884.1 & 889.1 & 894.3 \\
\hline 323.15 & 854.9 & 856.0 & 857.1 & 858.1 & 858.4 & 860.3 & 865.4 & 870.2 & 874.7 & 879.1 & 884.3 & 889.7 \\
\hline 328.15 & 849.2 & 850.2 & 851.3 & 852.5 & 852.9 & 854.7 & 860.0 & 865.0 & 869.6 & 874.0 & 879.4 & 884.9 \\
\hline 333.15 & 843.1 & 844.2 & 845.4 & 846.6 & 847.0 & 849.0 & 854.6 & 859.7 & 864.5 & 869.2 & 874.8 & 880.6 \\
\hline 338.15 & 836.9 & 838.2 & 839.5 & 840.7 & 841.1 & 843.1 & 848.8 & 854.4 & 859.4 & 863.6 & 869.9 & 875.8 \\
\hline 343.15 & 831.1 & 832.2 & 833.5 & 834.8 & 835.2 & 837.4 & 843.4 & 848.9 & 854.0 & 859.1 & 865.0 & 871.0 \\
\hline 348.15 & 824.9 & 826.0 & 827.4 & 828.8 & 829.3 & 831.5 & 837.7 & 843.4 & 848.8 & 854.0 & 860.1 & 866.3 \\
\hline 353.15 & 818.7 & 819.9 & 821.3 & 822.7 & 823.2 & 825.6 & 832.1 & 838.0 & 843.5 & 848.9 & 855.3 & 861.6 \\
\hline 363.15 & 803.5 & 805.1 & 806.9 & 808.7 & 809.3 & 812.0 & 819.6 & 826.5 & 833.0 & 839.1 & 844.8 & 850.2 \\
\hline 373.15 & 790.9 & 792.6 & 794.5 & 796.4 & 797.1 & 800.0 & 808.2 & 815.6 & 822.5 & 829.0 & 834.9 & 840.6 \\
\hline 383.15 & - & 780.0 & 782.1 & 784.1 & 784.8 & 787.9 & 796.6 & 804.6 & 811.9 & 818.7 & 825.0 & 830.9 \\
\hline 393.15 & - & 766.4 & 768.7 & 770.8 & 771.5 & 775.0 & 784.5 & 793.1 & 800.8 & 808.0 & 814.7 & 820.9 \\
\hline
\end{tabular}

Table 3. Experimental Density, $\rho$, Data for Ethyl Butyrate as a Function of Temperature, $T$, and Pressure, $P$

\begin{tabular}{|c|c|c|c|c|c|c|c|c|c|c|c|c|}
\hline \multirow[b]{2}{*}{$T / \mathrm{K}$} & \multicolumn{12}{|c|}{$\rho / \mathrm{kg} \cdot \mathrm{m}^{-3}$ at $P / \mathrm{MPa}$} \\
\hline & 0.10 & 1.00 & 2.00 & 3.00 & 3.10 & 5.00 & 10.00 & 15.00 & 20.00 & 25.00 & 30.00 & 35.00 \\
\hline 298.15 & 873.3 & 874.1 & 875.0 & 875.9 & 876.0 & 877.5 & 881.5 & 885.3 & 889.0 & 892.5 & 896.9 & 901.4 \\
\hline 303.15 & 868.1 & 868.9 & 869.8 & 870.7 & 870.7 & 872.4 & 876.5 & 880.4 & 884.1 & 887.8 & 892.3 & 896.9 \\
\hline 308.15 & 862.6 & 863.5 & 864.4 & 865.3 & 865.4 & 867.1 & 871.4 & 875.5 & 879.4 & 883.1 & 887.8 & 892.5 \\
\hline 313.15 & 857.3 & 858.2 & 859.1 & 860.1 & 860.2 & 861.9 & 866.3 & 870.5 & 874.5 & 878.4 & 883.2 & 888.1 \\
\hline 318.15 & 851.9 & 852.8 & 853.8 & 854.8 & 854.9 & 856.7 & 861.3 & 865.8 & 869.9 & 874.1 & 879.0 & 884.1 \\
\hline 323.15 & 846.7 & 847.4 & 848.4 & 849.5 & 849.6 & 851.7 & 856.7 & 861.1 & 865.4 & 869.4 & 874.5 & 879.7 \\
\hline 328.15 & 841.4 & 842.0 & 843.3 & 844.5 & 844.6 & 846.6 & 851.5 & 856.2 & 860.5 & 864.8 & 870.0 & 875.3 \\
\hline 333.15 & 835.8 & 837.0 & 838.1 & 839.2 & 839.3 & 841.2 & 846.3 & 851.1 & 855.6 & 860.1 & 865.4 & 870.8 \\
\hline 338.15 & 830.3 & 831.5 & 832.6 & 833.8 & 833.9 & 835.9 & 841.2 & 846.2 & 850.8 & 855.5 & 861.0 & 866.5 \\
\hline 343.15 & 824.8 & 825.9 & 827.1 & 828.3 & 828.4 & 830.7 & 836.2 & 841.4 & 846.1 & 850.1 & 855.7 & 861.8 \\
\hline 348.15 & 819.1 & 820.3 & 821.6 & 822.9 & 823.0 & 825.1 & 830.9 & 836.2 & 841.1 & 846.0 & 851.8 & 857.7 \\
\hline 353.15 & 813.5 & 814.7 & 816.1 & 817.4 & 817.5 & 819.8 & 825.7 & 831.2 & 836.3 & 841.4 & 847.4 & 853.4 \\
\hline 363.15 & 799.9 & 801.4 & 803.0 & 804.5 & 804.7 & 807.9 & 814.4 & 820.7 & 826.7 & 832.4 & 837.7 & 842.7 \\
\hline 373.15 & 788.5 & 790.1 & 791.7 & 793.4 & 793.6 & 796.8 & 804.0 & 810.8 & 817.2 & 823.1 & 828.7 & 834.0 \\
\hline 383.15 & 776.9 & 778.6 & 780.4 & 782.2 & 782.4 & 785.5 & 793.5 & 800.8 & 807.5 & 813.8 & 819.6 & 825.2 \\
\hline 393.15 & 765.1 & 766.9 & 768.8 & 770.8 & 771.0 & 774.5 & 783.1 & 790.9 & 798.0 & 804.6 & 810.7 & 816.6 \\
\hline
\end{tabular}

Table 4. Experimental Density, $\rho$, Data for Ethyl Pentanoate as a Function of Temperature, $T$, and Pressure, $P$

\begin{tabular}{|c|c|c|c|c|c|c|c|c|c|c|c|c|}
\hline \multirow[b]{2}{*}{$T / \mathrm{K}$} & \multicolumn{12}{|c|}{$\rho / \mathrm{kg} \cdot \mathrm{m}^{-3}$ at $P / \mathrm{MPa}$} \\
\hline & 0.10 & 1.00 & 2.00 & 2.78 & 3.00 & 5.00 & 10.00 & 15.00 & 20.00 & 25.00 & 30.00 & 35.00 \\
\hline 298.15 & 870.7 & 871.5 & 872.4 & 873.0 & 873.2 & 875.1 & 879.4 & 883.4 & 887.3 & 891.0 & 894.6 & 898.1 \\
\hline 303.15 & 865.5 & 866.4 & 867.4 & 868.1 & 868.3 & 870.1 & 874.5 & 878.7 & 882.6 & 886.5 & 890.2 & 893.8 \\
\hline 313.15 & 855.0 & 855.9 & 856.9 & 857.7 & 857.9 & 859.9 & 864.5 & 868.9 & 873.0 & 877.0 & 880.9 & 884.6 \\
\hline 318.15 & 849.8 & 850.6 & 851.7 & 852.4 & 852.7 & 854.6 & 859.4 & 863.9 & 868.2 & 872.3 & 876.3 & 880.1 \\
\hline 323.15 & 844.4 & 845.3 & 846.4 & 847.2 & 847.4 & 849.4 & 854.3 & 859.0 & 863.4 & 867.6 & 871.7 & 875.5 \\
\hline 338.15 & 828.4 & 829.5 & 830.7 & 831.5 & 831.8 & 834.0 & 839.4 & 844.5 & 849.3 & 853.9 & 858.2 & 862.4 \\
\hline 343.15 & 823.0 & 824.1 & 825.3 & 826.2 & 826.5 & 828.8 & 834.4 & 839.6 & 844.5 & 849.2 & 853.7 & 858.0 \\
\hline 348.15 & 817.7 & 818.7 & 820.0 & 821.0 & 821.3 & 823.7 & 829.4 & 834.8 & 839.9 & 844.7 & 849.3 & 853.6 \\
\hline 353.15 & 812.2 & 813.3 & 814.6 & 815.6 & 815.9 & 818.4 & 824.3 & 829.9 & 835.1 & 840.0 & 844.7 & 849.1 \\
\hline 363.15 & 801.2 & 802.5 & 803.9 & 805.0 & 805.5 & 808.1 & 814.6 & 820.5 & 826.0 & 831.2 & 836.0 & 840.8 \\
\hline 373.15 & 790.7 & 792.0 & 793.5 & 794.7 & 795.0 & 797.9 & 804.8 & 810.9 & 816.7 & 822.2 & 827.3 & 832.3 \\
\hline 383.15 & 779.9 & 781.3 & 783.0 & 784.2 & 784.5 & 787.6 & 795.0 & 801.5 & 807.6 & 813.4 & 818.9 & 824.0 \\
\hline
\end{tabular}

In eq 2 , the coefficient $C$ was treated as constant for each substance while the parameter $B$ was considered temperature dependent following a function proposed by Kumagai and Iwasaki. $^{23}$ They have found that $B$ is proportional to the reciprocal of temperature. This dependence is given by

$$
B=b_{1}+\frac{b_{2}}{T}
$$

where $b_{1}$ and $b_{2}$ are parameters obtained from the fitting of eq 2 to PVT data. In Table 8 , we list the parameters of the Tait equation, the average absolute deviation (AAD), and the standard deviation of the fittings $(\sigma)$ for the esters studied.
Table 5. Critical Constants $\left(T_{c}, P_{c}\right)$ and Parameters of the Wagner Equation, Equation $3^{a}$ and the Antoine Equation, Equation $4^{b}$

\begin{tabular}{|c|c|c|c|c|c|c|}
\hline \multirow[b]{2}{*}{ ester } & \multirow{2}{*}{$\frac{T_{\mathrm{c}}}{\mathrm{K}}$} & \multirow{2}{*}{$\frac{P_{\mathrm{c}}}{\mathrm{kPa}}$} & \multicolumn{4}{|c|}{ parameters of eqs 3 and 4} \\
\hline & & & $n_{1}$ & $n_{2}$ & $n_{3}$ & $n_{4}$ \\
\hline $\begin{array}{l}\text { ethyl } \\
\text { propionate }\end{array}$ & $546.1^{c}$ & $3360^{c}$ & -7.76801 & 1.19545 & -3.81174 & -3.81174 \\
\hline $\begin{array}{l}\text { ethyl } \\
\text { butyrate }\end{array}$ & $569.0^{c}$ & $2950^{c}$ & -7.93351 & 1.22092 & -3.89295 & -3.89295 \\
\hline $\begin{array}{l}\text { ethyl } \\
\text { pentanoate }\end{array}$ & $593.3^{d}$ & $2780^{e}$ & 15.3818 & 4074.13 & -40.59 & \\
\hline
\end{tabular}

${ }^{a}$ The parameters are from ref $17 .{ }^{b}$ Parameters from ref $18 .{ }^{c}$ Ref 17. ${ }^{d} \operatorname{Ref} 19 .{ }^{e} \operatorname{Ref} 20$ 


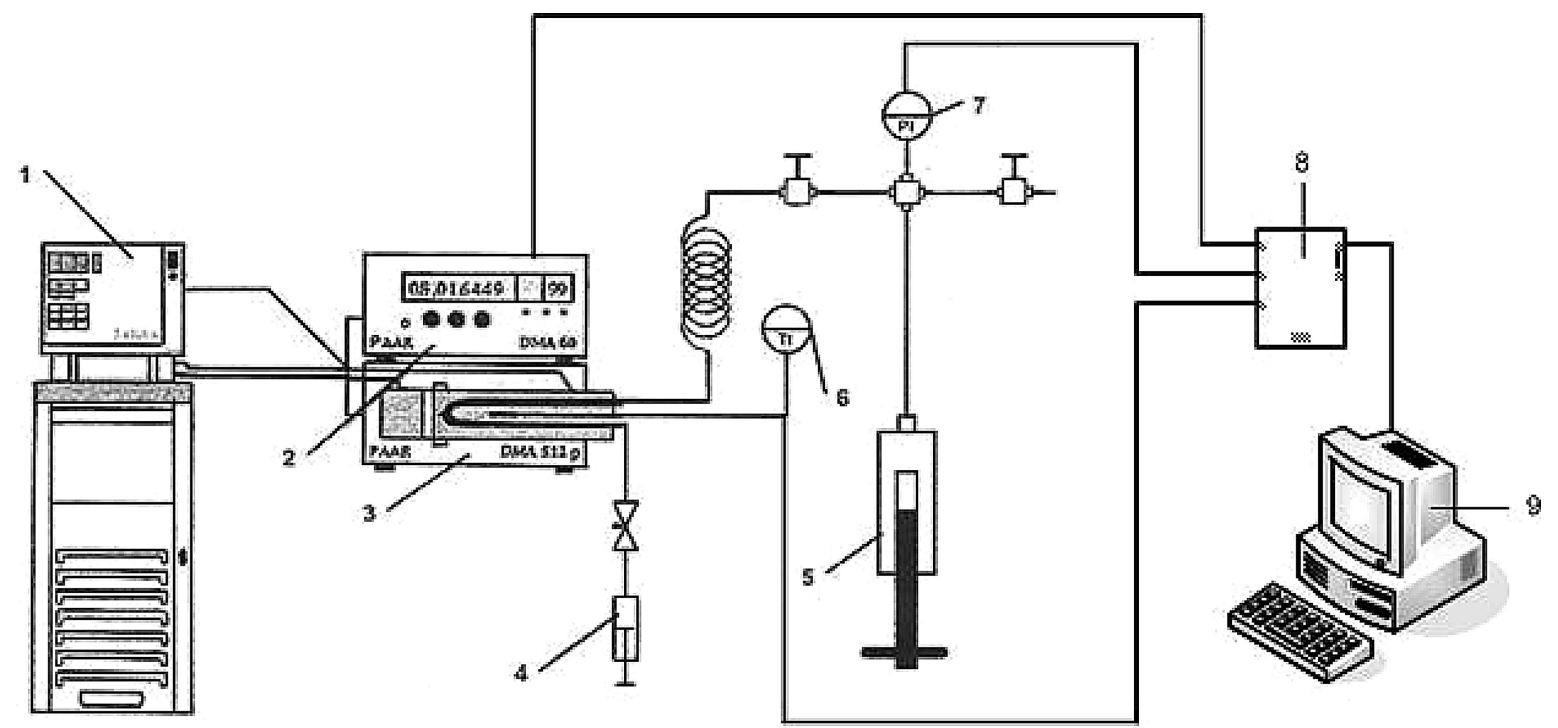

Figure 1. Experimental setup for the measurement of liquid densities at high pressures: 1, Julabo FP-50 thermostatic bath; 2 , DMA 60 (Anton Paar) device for measuring the period of oscillation; 3, measuring cell DMA 512P (Anton Paar); 4, syringe for sample introduction; 5, pressure generator model HIP 50-6-15; 6, PT probe; 7, pressure transducer WIKA, S-10; 8, NI PCI-8220 data acquisition board; 9, PC.

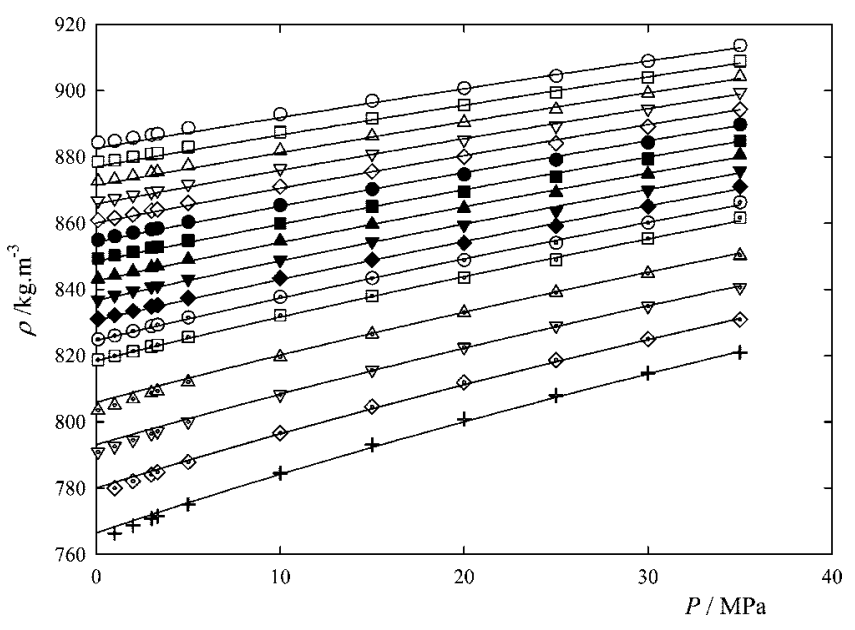

Figure 2. Isotherms of the density $(\rho)$ for ethyl propionate. The symbols refer to the experimental data: from $\bigcirc, 298.15 \mathrm{~K}$ to $\odot, 353.15 \mathrm{~K}$ with increments of $5 \mathrm{~K}$, and from $\square, 353.15 \mathrm{~K}$ to,$+ 393.15 \mathrm{~K}$ with increments of $10 \mathrm{~K}$. The curves are calculated with eq 2.

In Figure 5, the percentage density deviation plots between the calculated values with eq 2 and experimental data are shown. The absolute percentage deviations are less than $0.2 \%$ in the majority part of the temperature and pressure domains. The AAD is of the order of $0.1 \%$ for all the substances (see Table 8).

Some mechanical coefficients were obtained from the Tait equation. For the isothermal compressibility $\left(k_{T}\right)$ defined as

$$
k_{T}=-\frac{1}{V_{\mathrm{m}}}\left(\frac{\delta V_{\mathrm{m}}}{\delta P}\right)_{T}=\frac{1}{\rho}\left(\frac{\delta \rho}{\delta P}\right)_{T}=\left(\frac{\delta \ln \rho}{\delta P}\right)_{T}
$$

the final expression is

$$
k_{T}=\left(\frac{C}{B+P}\right)\left(\frac{\rho}{\rho, \sigma}\right)
$$

The isothermal compressibilities of the esters are listed as Supporting Information, and the values for ethyl propionate are shown in Figure 6. For the other alkyl esters, the representations are similar.

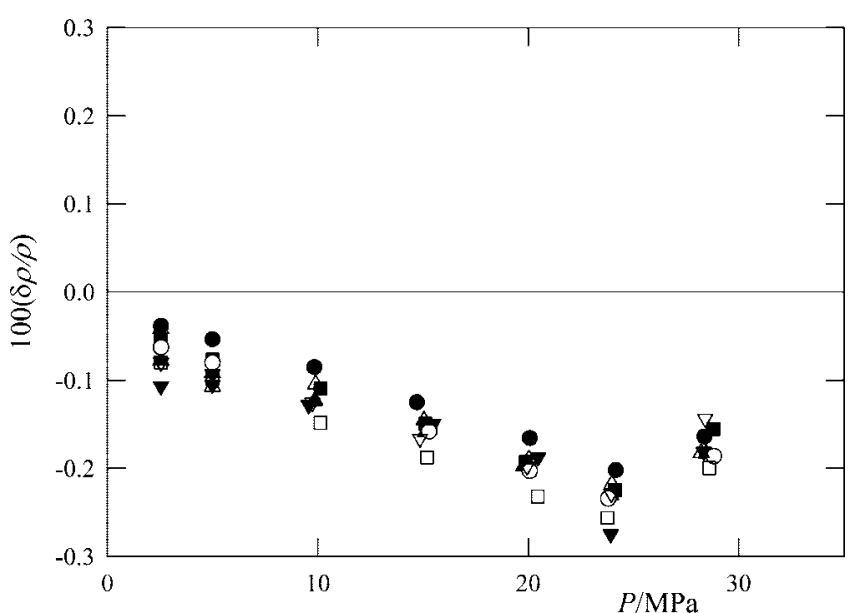

Figure 3. Percentage deviations between experimental data of this work and that from Malhotra and Woolf ${ }^{9}$ at the temperatures of $\bullet, \bigcirc, 298.14 \mathrm{~K}$; $\mathbf{\square}, \square, 313.14 \mathrm{~K} ; \mathbf{\Lambda}, \Delta, 323.14 \mathrm{~K} ; \boldsymbol{\nabla}, \nabla, 338.13 \mathrm{~K}$. The full symbols refer to the ethyl propionate and the open symbols to ethyl butyrate. The quantity $100(\delta \rho / \rho)$ means $100\left(\rho_{\text {eq } 2}-\rho_{\text {lit. }}\right) / \rho_{\text {lit. }}$.

For the isobaric expansivity $\left(\alpha_{P}\right)$

$$
\alpha_{P}=\frac{1}{V_{\mathrm{m}}}\left(\frac{\delta V_{\mathrm{m}}}{\delta T}\right)_{P}=-\frac{1}{\rho}\left(\frac{\delta \rho}{\delta T}\right)_{P}=-\left(\frac{\delta \ln \rho}{\delta T}\right)_{P}
$$

the following expression is derived from the Tait and the Rackett equations

$$
\begin{aligned}
& \alpha_{P}=-\frac{2}{7} \frac{\ln \left(Z_{\mathrm{RA}}\right)}{T_{\mathrm{c}}\left(1-T_{\mathrm{r}}\right)^{5 / 7}}- \\
& \qquad\left\{\frac{\frac{\mathrm{d} B}{\mathrm{~d} T}\left(P^{\sigma}-P\right)-\gamma^{\sigma}(B+P)}{\left[1-C \ln \left(\frac{B+P}{B+P^{\sigma}}\right)\right]\left(B+P^{\sigma}\right)(B+P)}\right\}
\end{aligned}
$$

where $\mathrm{d} B / \mathrm{d} T=-b_{2} / T^{2}$ and $\gamma^{\sigma}=\mathrm{d} P^{\sigma} / \mathrm{d} T$ is the slope of the vapor pressure curve at the given temperature $T$. The values of $\alpha_{P}$ are plotted in Figure 7 for ethyl butyrate. Values of this mechanical coefficient for the other esters are given as Supporting Information. 
Table 6. Density of the Saturated Liquid, $\rho^{\ell, \sigma}$

\begin{tabular}{|c|c|c|c|c|c|c|c|}
\hline$T$ & $\rho^{\ell, \sigma}$ & $T$ & $\rho^{l, \sigma}$ & $T$ & $\rho^{\ell, \sigma}$ & $T$ & $\rho^{\ell, \sigma}$ \\
\hline $\mathrm{K}$ & $\mathrm{kg} \cdot \mathrm{m}^{-3}$ & $\mathrm{~K}$ & $\mathrm{~kg} \cdot \mathrm{m}^{-3}$ & K & $\mathrm{kg} \cdot \mathrm{m}^{-3}$ & $\mathrm{~K}$ & $\mathrm{~kg} \cdot \mathrm{m}^{-3}$ \\
\hline \multicolumn{8}{|c|}{ Ethyl Propionate } \\
\hline 298.15 & 884.1 & 318.15 & 860.7 & 338.15 & 836.9 & 363.15 & 803.5 \\
\hline 303.15 & 878.3 & 323.15 & 854.9 & 343.15 & 831.0 & 373.15 & 790.9 \\
\hline 308.15 & 872.5 & 328.15 & 849.1 & 348.15 & 824.8 & 383.15 & 778.3 \\
\hline 313.15 & 866.6 & 333.15 & 843.0 & 353.15 & 818.6 & 393.15 & 764.7 \\
\hline \multicolumn{8}{|c|}{ Ethyl Butyrate } \\
\hline 298.15 & 873.2 & 318.15 & 851.8 & 338.15 & 830.2 & 363.15 & 799.8 \\
\hline 303.15 & 868.0 & 323.15 & 846.5 & 343.15 & 824.7 & 373.15 & 788.4 \\
\hline 308.15 & 862.5 & 328.15 & 841.1 & 348.15 & 819.0 & 383.15 & 776.9 \\
\hline 313.15 & 857.2 & 333.15 & 835.8 & 353.15 & 813.4 & 393.15 & 765.1 \\
\hline \multicolumn{8}{|c|}{ Ethyl Pentanoate } \\
\hline 298.15 & 870.6 & 318.15 & 849.7 & 338.15 & 828.3 & 363.15 & 801.1 \\
\hline 303.15 & 865.4 & 323.15 & 844.3 & 343.15 & 822.9 & 373.15 & 790.6 \\
\hline 308.15 & 860.2 & 328.15 & 839.0 & 348.15 & 817.5 & 383.15 & 779.8 \\
\hline 313.15 & 855.0 & 333.15 & 33.6 & 353.15 & 812.1 & 393.15 & 768.9 \\
\hline
\end{tabular}

Table 7. Coefficient $Z_{\mathrm{RA}}$ in the Rackett Equation, Equation 5, Standard Deviation of the Fit, $\sigma$, and Average Absolute Deviation, AAD

\begin{tabular}{lcccccc}
\hline & & & & \multicolumn{2}{c}{$\rho_{\mathrm{c}} / \mathrm{kg} \cdot \mathrm{m}^{-3}$} \\
\cline { 5 - 7 } \multicolumn{1}{c}{ ester } & $Z_{\mathrm{RA}}$ & $\sigma / \mathrm{kg} \cdot \mathrm{m}^{-3}$ & $\mathrm{AAD} \%$ & eq 5 & lit. \\
\hline ethyl propionate & $0.2549 \pm 0.0001$ & 1.4 & 0.13 & 296.5 & $296.0^{a}$ \\
ethyl butyrate & $0.2527 \pm 0.0000$ & 1.1 & 0.10 & 286.6 & $275.9^{a}$ \\
ethyl pentanoate & $0.2573 \pm 0.0001$ & 2.1 & 0.21 & 285.2 & $289.9^{a}$
\end{tabular}

${ }^{a} \operatorname{Ref} 20$.

The thermal pressure coefficient $\left(\gamma_{\mathrm{V}}\right)$ was calculated according to

$$
\gamma_{\mathrm{V}}=\left(\frac{\delta P}{\delta T}\right)_{\rho}=\frac{\alpha_{P}}{k_{T}}
$$

and the values for this property are plotted in Figure 8 for ethyl pentanoate. The thermal pressure coefficient data for ethyl propionate and ethyl butyrate are also given as Supporting Information. We have performed a statistical study to determine the correct number of significant figures of the mechanical coefficients. We have applied the propagation law of errors at eqs 9,11 , and 12 taking into account the uncertainties in the parameters $Z_{\mathrm{RA}}, C, b_{1}$, and $b_{2}$ and also in the temperature and pressure. We have concluded that the calculated $k_{T}$ must be presented with no more than one decimal place, and the $\alpha_{P}$ can be written with two or one decimals depending on the $(T, P)$ domain considered. Obviously $\gamma_{\mathrm{V}}$ must be presented with only one decimal place. The values of $\alpha_{P}$ are similar in magnitude for all the esters in the tested ranges of temperature and pressure. The same is true for $k_{T}$. The dependence on $P$ and $T$ of these mechanical coefficients follows the expected behavior. The coefficients $\alpha_{P}$ and $k_{T}$ show an increase with the temperature which is more significant at lower pressures. At high pressures, the value of $\alpha_{P}$ is practically constant, independent of temperature. At fixed pressure, the value of the thermal pressure coefficient decreases with the increasing temperature, and an isothermal increase with pressure in this property is observed, especially at values of high temperature isotherms. From the tables given in the Supporting Information, it is observed that the effect of adding $-\mathrm{CH}_{2}-$ units to the alkanoate group of the ester molecule has negligible changes on the mechanical coefficients.

The $\alpha_{P}$ and $k_{T}$ data from this work have been compared with the values reported by Malhotra and Woolf ${ }^{9}$ for ethyl propionate and ethyl butyrate. The absolute percentage deviation for both coefficients is between ( 1 and 3) \%, and therefore the agreement can be considered good because these coefficients involve the derivatives of density which are highly sensible to minor changes in the density.
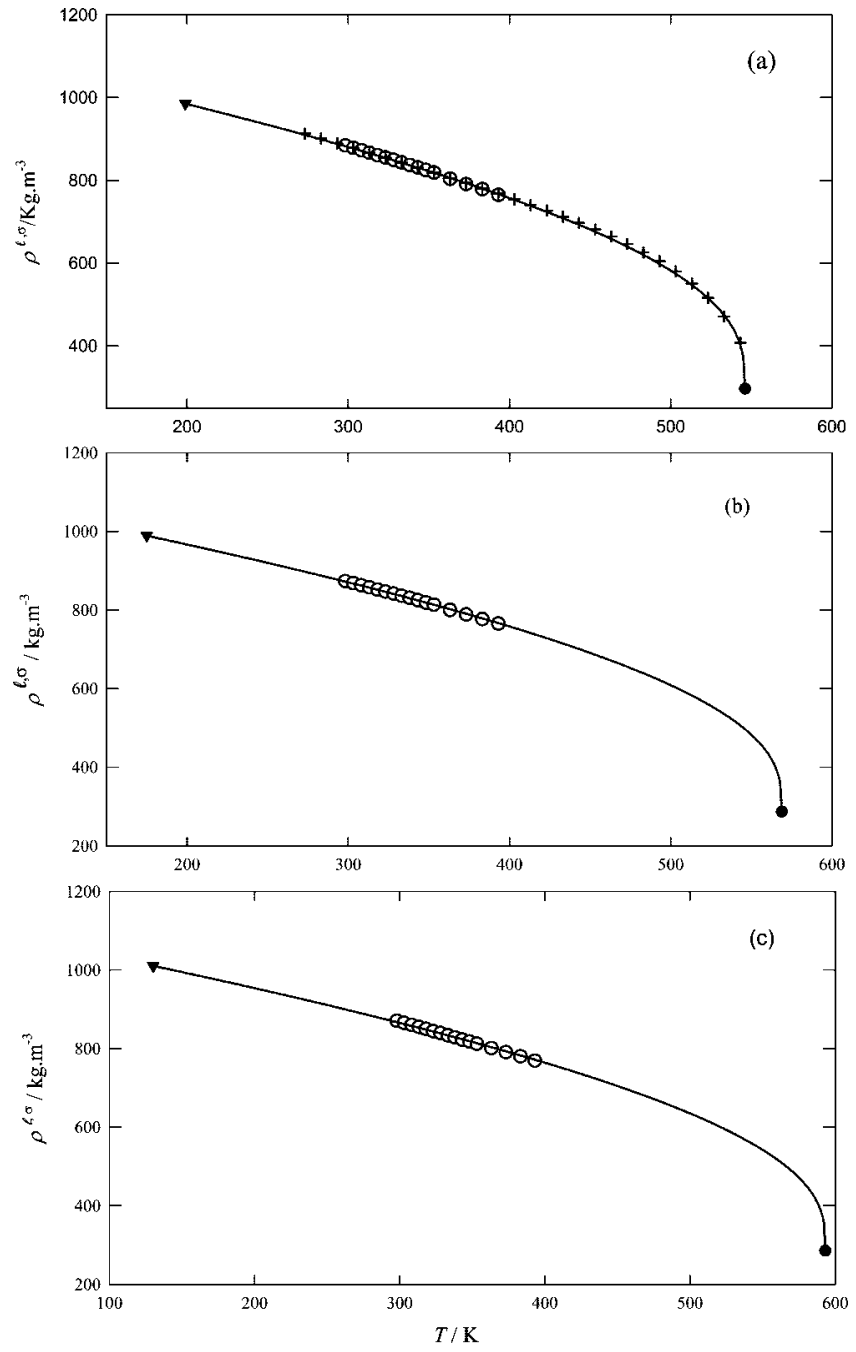

Figure 4. Density of the saturated liquid of the alkyl esters $\left(\rho^{\prime \sigma}\right)$ as a function of temperature. Full curves are calculated from eq 5 with the value $Z_{\mathrm{RA}}$ from this work: $\boldsymbol{\nabla}$, triple point; $\boldsymbol{\bullet}$, critical point. (a) Ethyl propionate: + , ref 22; (b) ethyl butyrate; (c) ethyl pentanoate. $\bigcirc$, This work.

Table 8. Coefficients of Equation 2 and Equation 7, Standard Deviation of the Fit, $\sigma$, and Average Absolute Deviation, AAD

\begin{tabular}{|c|c|c|c|c|c|}
\hline & & $b_{1}$ & $b_{2}$ & $\sigma$ & $\mathrm{AAD}$ \\
\hline ester & $C$ & $\mathrm{MPa}$ & $\mathrm{MPa} \cdot \mathrm{K}$ & $\mathrm{kg} \cdot \mathrm{m}^{-3}$ & $\%$ \\
\hline ethyl propi & 0.138 & -170.04 & 88936.6 & 0.8 & 0.07 \\
\hline ethyl butyrate & 0.140 & -171.8 & 92378.0 & 0.7 & 0.07 \\
\hline ethyl pentanoate & 0.103 & -48.123 & 40984.3 & 1.4 & 0.14 \\
\hline
\end{tabular}

Taking into account the influence of pressure on the isobaric molar heat capacity $\left(C_{\mathrm{P}, m}\right)$ at constant temperature

$$
\left(\frac{\partial C_{\mathrm{P}, \mathrm{m}}}{\partial P}\right)_{T}=-T\left(\frac{\partial^{2} V_{\mathrm{m}}}{\partial T^{2}}\right)_{P}
$$

the following equation is obtained for the change in the isobaric molar heat capacity due to the increase in the pressure from $0.1 \mathrm{MPa}$ to $P$

$$
\begin{aligned}
\Delta C_{\mathrm{P}, \mathrm{m}}(T, P)=C_{\mathrm{P}, \mathrm{m}}(T, P) & -C_{\mathrm{P}, \mathrm{m}}(T, P=0.1 \mathrm{MPa})= \\
& -T \int_{0.1}^{P}\left\{\frac{M}{\rho}\left[\left(\frac{\partial \alpha_{P}}{\partial T}\right)_{P}+\left(\alpha_{P}\right)^{2}\right]\right\} \mathrm{d} P
\end{aligned}
$$

where $M$ is the molar mass. The quantities in the integrand of eq 14 were calculated from the Tait equation. The values of $\Delta C_{\mathrm{P}, \mathrm{m}}$ are given also in the Supporting Information and can be 

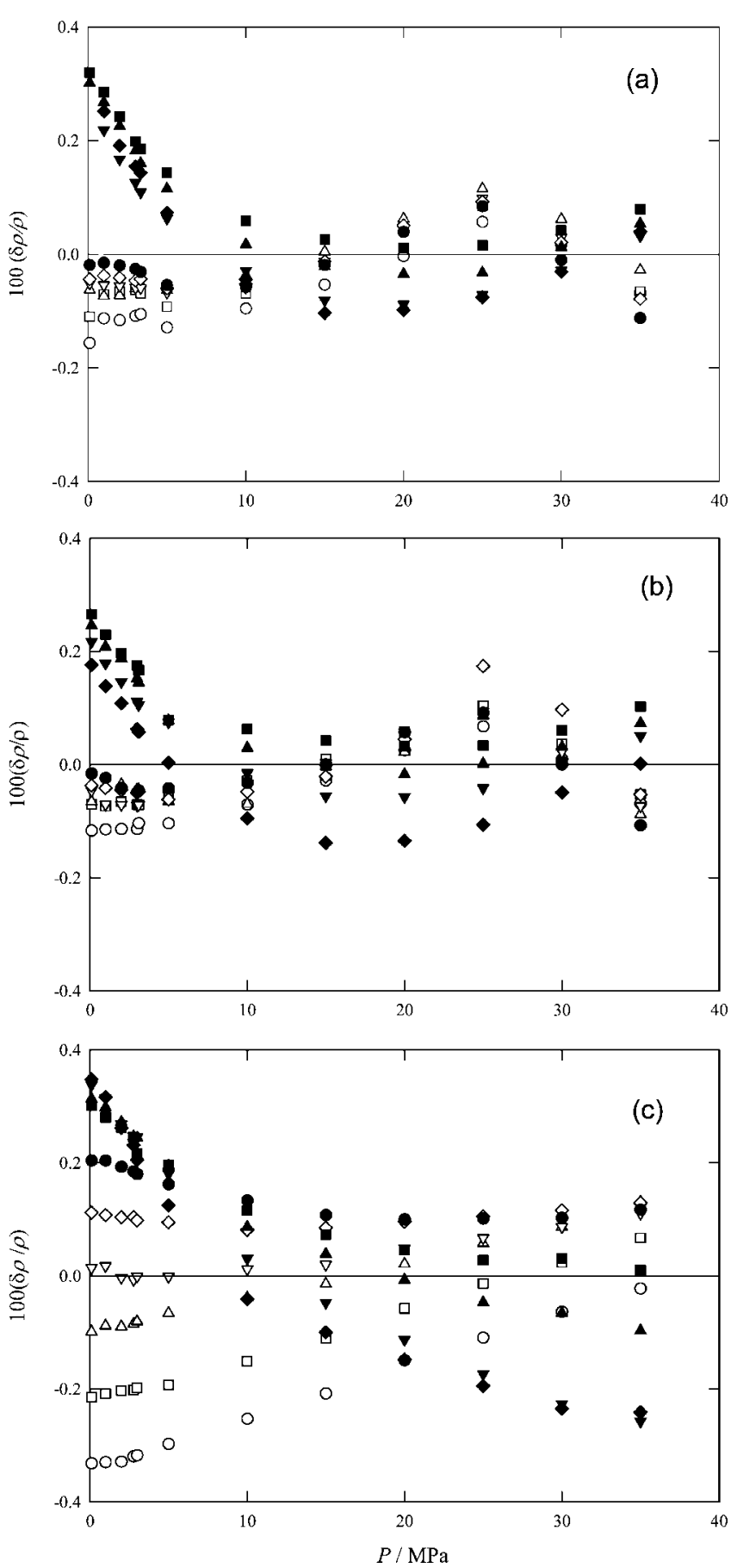

Figure 5. Percentage density deviations between the values obtained with eq 2 and experimental data: (a) ethyl propionate; (b) ethyl butyrate; (c) ethyl pentanoate. Experimental data at the temperatures of $\bigcirc, 303.15 \mathrm{~K}$; $\square, 313.15 \mathrm{~K} ; \Delta, 323.15 \mathrm{~K} ; \nabla, 333.15 \mathrm{~K} ; \diamond, 343.15 \mathrm{~K} ; \bullet, 353.15 \mathrm{~K} ; \mathbf{\square}$, $363.15 \mathrm{~K} ; \boldsymbol{\Delta}, 373.15 \mathrm{~K} ; \boldsymbol{\nabla}, 383.15 \mathrm{~K} ; \diamond, 393.15 \mathrm{~K}$. The quantity $100(\delta \rho / \rho)$ means $100\left(\rho_{\text {eq } 2}-\rho_{\text {expt } 1}\right) / \rho_{\text {exptt }}$.

estimated to have an error of $( \pm 1$ to 2$) \mathrm{J} \cdot \mathrm{mol}^{-1} \cdot \mathrm{K}^{-1}$. The most appreciable changes in $C_{\mathrm{P}, \mathrm{m}}$ occur at high pressure and high temperature. However, in the range of pressures covered by this work, the $\Delta C_{\mathrm{P}, \mathrm{m}}$ is small compared with the value of $C_{\mathrm{P}, \mathrm{m}}(T, P=0.1 \mathrm{MPa})$. Following the data compiled by Zábranský et al. ${ }^{24}$ for ethyl propionate, the highest temperature available for comparison is $350 \mathrm{~K}$. At this temperature and atmospheric pressure, $C_{\mathrm{P}, \mathrm{m}}=211 \mathrm{~J} \cdot \mathrm{mol}^{-1} \cdot \mathrm{K}^{-1}$ and $\Delta C_{\mathrm{P}, \mathrm{m}}(350$ $\mathrm{K}, 35 \mathrm{MPa})=-8 \mathrm{~J} \cdot \mathrm{mol}^{-1} \cdot \mathrm{K}^{-1}$. For ethyl butyrate, $C_{\mathrm{P}, \mathrm{m}}(350$ $\mathrm{K}, 0.1 \mathrm{MPa})=248 \mathrm{~J} \cdot \mathrm{mol}^{-1} \cdot \mathrm{K}^{-1}$ and $\Delta C_{\mathrm{P}, \mathrm{m}}(350 \mathrm{~K}, 35 \mathrm{MPa})$ $=-7 \mathrm{~J} \cdot \mathrm{mol}^{-1} \cdot \mathrm{K}^{-1}$.

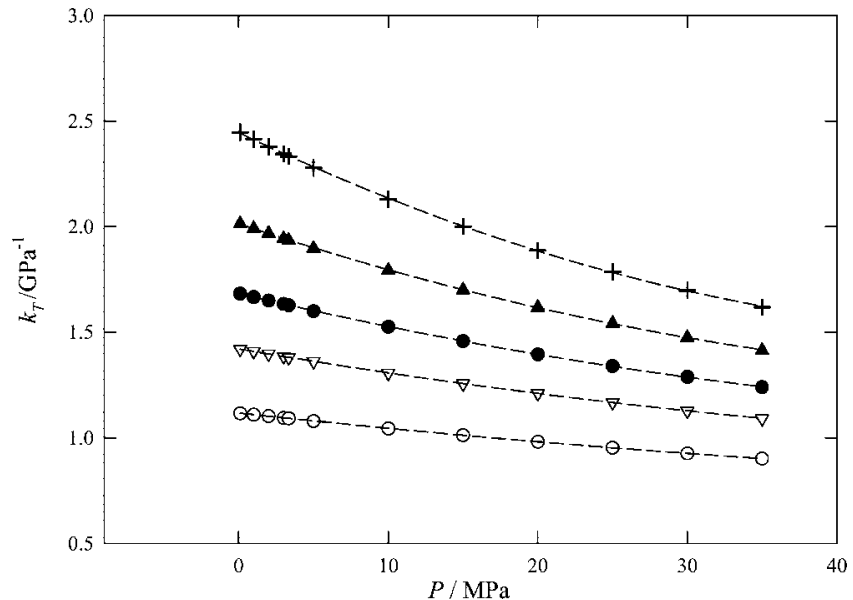

Figure 6. Isothermal compressibility of ethyl propionate at the temperatures: O, $303.15 \mathrm{~K} ; \nabla, 333.15 \mathrm{~K} ; \bullet$ •, $353.15 \mathrm{~K} ; \boldsymbol{\Delta}, 373.15 \mathrm{~K} ;+$, $393.15 \mathrm{~K}$. The curves were fitted to data.

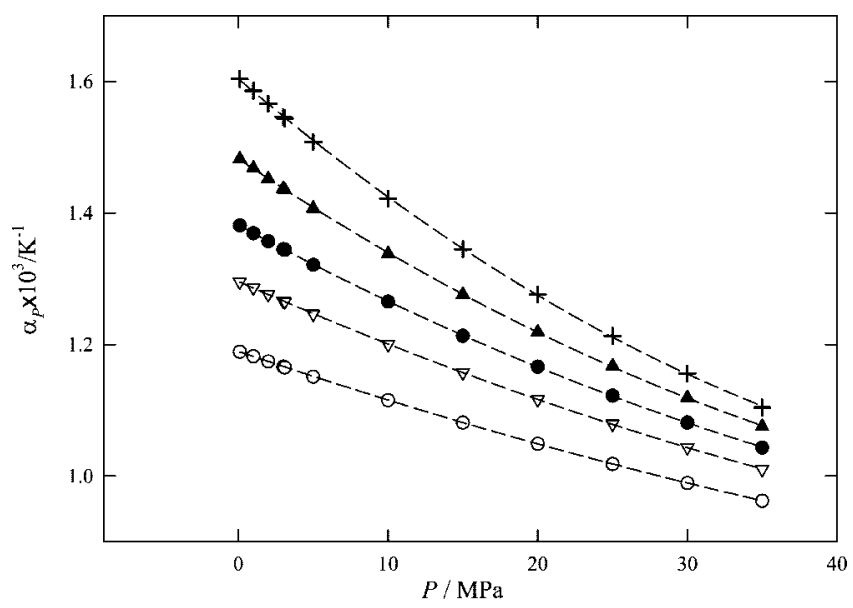

Figure 7. Isobaric expansivity of ethyl butyrate at the temperatures: $O$, $303.15 \mathrm{~K} ; \nabla, 333.15 \mathrm{~K} ; \bullet$ •, $353.15 \mathrm{~K} ; \mathbf{\Delta}, 373.15 \mathrm{~K} ;+$, $393.15 \mathrm{~K}$. The curves were fitted to data.

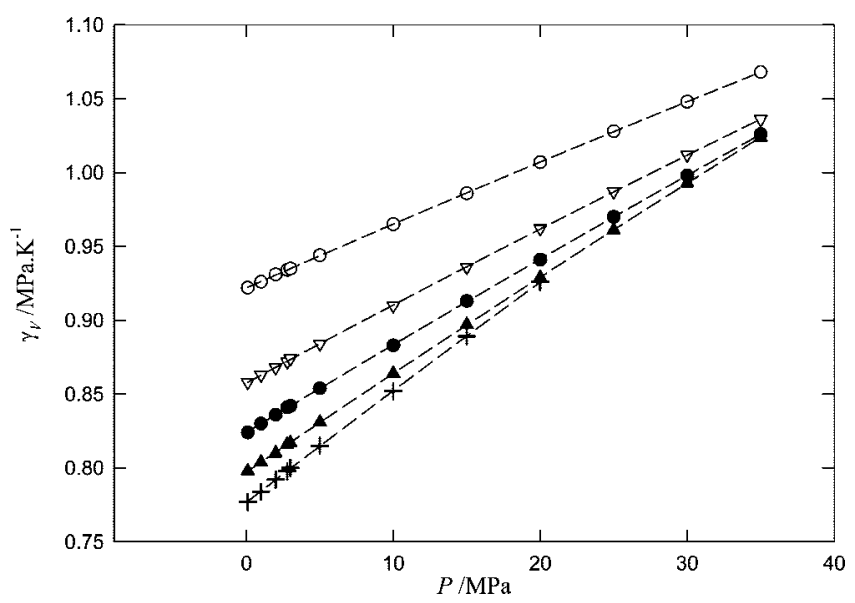

Figure 8. Thermal pressure of ethyl pentanoate at the temperatures: $\bigcirc$, $303.15 \mathrm{~K} ; \nabla, 333.15 \mathrm{~K} ; \bullet$ •, $353.15 \mathrm{~K}$; $\mathbf{\Delta}, 373.15 \mathrm{~K}$; +, $393.15 \mathrm{~K}$. The curves were fitted to data.

The Tait equation was also used to predict the density of the ethyl alkanoates studied here. For this purpose, the method due to Thomson et al. ${ }^{12}$ was applied. In this method, the parameters $B$ and $C$ of eq 1 are predicted by the following equations

$$
\begin{aligned}
& B / P_{\mathrm{c}}=-1.0+a\left(1-T_{\mathrm{r}}\right)^{1 / 3}+b\left(1-T_{\mathrm{r}}\right)^{2 / 3}+ d\left(1-T_{\mathrm{r}}\right)+ \\
& e\left(1-T_{\mathrm{r}}\right)^{4 / 3}(15)
\end{aligned}
$$




$$
\begin{gathered}
C=j+k \omega \\
e=\exp \left(f+g \omega+h \omega^{2}\right)
\end{gathered}
$$

were $\omega$ is the Pitzer acentric factor and $a=-9.070217, b=$ 62.45326, $d=-135.1102, f=4.79594, g=0.250047, h=$ $1.14188, j=0.0861488$, and $k=0.0344483$. The necessary vapor pressure and saturated liquid densities to be used in eq 2 were provided by eqs 3 to 5 . The AAD between experimental and predicted values of density is $0.6 \%$.

\section{Conclusions}

In this work, experimental density data of ethyl alkanoates (propionate, butyrate, and pentanoate) over the pressure range (0.1 to 35) $\mathrm{MPa}$ and the temperature range (298.15 to 393.15) $\mathrm{K}$ are presented. We have extended the temperature domains of the experimental measurements for ethyl propionate and ethyl butyrate considering the available literature data. Our measurements are in close agreement in the $(P, T)$ domain covered by other authors. As far as we know, density data for the ethyl pentanoate at wide ranges of temperature and pressure are original. We have found that the density of the esters is essentially constant and decreases only slightly with the increase of the alkyl chain length. This behavior was already found in alkyl acetates investigated in a previous work.

The Tait equation was fitted to the density data using simultaneously the pressure and the temperature which is a more direct and fast methodology than to fit the equation to isothermal $(\rho, P)$ data, as some authors do. With this procedure, the mechanical coefficients $\alpha_{\mathrm{P}}, k_{T}$, and $\gamma_{\mathrm{V}}$ and the change in the isobaric molar heat capacity $\left(\Delta C_{\mathrm{P}, \mathrm{m}}\right)$, from $P=0.1 \mathrm{MPa}$ to $P$ at fixed $T$ were calculated in wide $(P, T)$ ranges. The values of these $P V T$ properties show a good agreement with those from other authors. The calculated values of the change in the isobaric heat capacity $\left(\Delta C_{\mathrm{P}, \mathrm{m}}\right)$ are always negative and represent less than $5 \%$ of the values of $C_{\mathrm{P}, \mathrm{m}}(T, P=0.1 \mathrm{MPa})$.

The method due to Thomson et al. can be applied to the prediction of density of the esters with satisfactory results.

\section{Supporting Information Available:}

An additional four tables. This material is available free of charge via the Internet at http://pubs.acs.org.

\section{Literature Cited}

(1) Gardas, R. L.; Johnson, I.; Vaz, D. M. D.; Fonseca, I. M. A.; Ferreira, A. G. M. PVT Property Measurements for Some Aliphatic Esters from 298 to $393 \mathrm{~K}$ and up to $35 \mathrm{MPa}$. J. Chem. Eng. Data 2007, 52, 737751.

(2) Visak, Z. P.; Ferreira, A. G. M.; Fonseca, I. M. A. Densities and viscosities of the ternary mixtures water+butyl acetate +methanol and water+ethyl propionate +methanol at 303.15 K. J. Chem. Eng. Data 2000, 45, 926-931.

(3) Santos, B. M. S.; Ferreira, A. G. M.; Fonseca, I. M. A. Surface and interfacial tensions of the systems water+n-butyl acetate+methanol and water+n-pentyl acetate+methanol at 303.15 K. Fluid Phase Equilib. 2003, 208, 1-21.

(4) Kijevcanin, M. L.; Ribeiro, I. S. A.; Ferreira, A. G. M.; Fonseca, I. M. A. Densities, Viscosities and surface and interfacial tensions of the ternary mixture water + ethyl butyrate + methanol at $303.15 \mathrm{~K}$. J. Chem. Eng. Data 2003, 48, 1266-1270.

(5) Kijevcanin, M. L.; Ribeiro, I. S. A.; Ferreira, A. G. M.; Fonseca, I. M. A. Water + esters + methanol: experimental data, correlation and prediction of surface and interfacial tensions at $303.15 \mathrm{~K}$ and atmospheric pressure. Fluid Phase Equilib. 2004, 218, 141-148.

(6) Resa, J. M.; González, C.; Landaluce, S. O.; Lanz, J. Density, Refractive Index, Speed of Sound, and Vapor-Liquid Equilibria for Binary Mixtures of Methanol+Ethyl Propionate and Vinyl Acetate + Ethyl Propionate. J. Chem. Eng. Data 2002, 47, 435-440.

(7) Oswal, S. L.; Oswal, P.; Modi, P. S.; Dave, J. P.; Gardas, R. L. Acoustic, volumetric, compressibility and refractivity properties and Flory's reduction parameters of some homologous series of alkyl alkanoates from 298.15 to 333.15 K. Thermochim. Acta 2004, 410, $1-14$.

(8) Resa, J. M.; González, C.; Landaluce, S. O.; Lanz, J. Density, Refractive Index, Speed of Sound, at $298.15 \mathrm{~K}$, and Vapor-Liquid Equilibria at $101.3 \mathrm{kPa}$ for Binary Mixtures of Methanol+Ethyl Butyrate and Vinyl Acetate + Ethyl Butyrate. J. Chem. Eng. Data 2002, 47, 1123-1127.

(9) Malhotra, R.; Woolf, L. A. PVT Property Measurements for the Liquids Ethyl propionate and Ethyl Butyrate from (298 to 338) K and (0.1 to 380) MPa. J. Chem. Eng. Data 1996, 41, 1371-1374.

(10) Francesconi, R.; Arcelli, A.; Comelli, F. Excess Properties of Binary Mixtures Containing 2-Methoxy-2-methylpropane (MTBE) and Akyl Alkanoates at 298.15 K. J. Chem. Eng. Data 1998, 43 (3), 329-332.

(11) Indraswati, N.; Mudjijati; Wicaksana, F.; Hindarso, H. Density and Viscosity for a Binary of Ethyl Valerate and Hexyl Acetate with 1Pentanol and 1-Hexanol at 293.15 K, 303.15 and 313.15 K. J. Chem. Eng. Data 2001, 46, 134-137.

(12) Thomson, G. H.; Brobst, K. R.; Hankinson, R. W. An improved correlation for densities of compressed liquids and liquid mixtures. AIChE J. 1982, 28, 671-676.

(13) Riddick, J. A.; Bunger, W. B.; Sakano, T. K. Organic Solvents Physical Properties and Methods of Purification, 4th ed.; Wiley Interscience: New York, 1986.

(14) Niesen, V. G. (Vapour + liquid) equilibria and coexisting densities of (carbon dioxide+n-butane) at 311 to 395K. J. Chem. Thermodyn. 1989, 21, 915-923.

(15) Holcomb, C. D.; Outcalt, S. L. A theoretical-based calibration and evaluation procedure for vibrating-tube densimeters. Fluid Phase Equilib. 1998, 815-827.

(16) Fandiño, O.; Pensado, S. A.; Lugo, L.; López, E. R.; Fernández, J. Volumetric behaviour of the environmentally compatible lubricants Pentaerythritol tetraheptanoate and Pentaerythritol tetranonanoate at high pressures. Green Chem. 2005, 7, 775-783.

(17) Vapour pressures and critical points of liquids XVI: Esters of aliphatic carboxylic acids; Engineering Sciences Data N. 80019, 1980.

(18) Carelli, A. A.; Crapiste, G. H.; Lozano, F. E. Activity coefficients of aroma compounds in model solutions simulating apple juice. J. Agric. Food Chem. 1991, 39, 1636-1640.

(19) Morton, D. W.; Lui, M.; Young, C. L. The (gas + liquid) critical temperatures of some ethers, esters, and ketones. J. Chem. Thermodyn. 1999, 31, 675-684.

(20) Poling, B. E.; Prausnitz, J. M.; O'Connel J. P. The Properties of Gases and Liquid, 5th ed.; McGraw-Hill: New York, 2001.

(21) Spencer, C. F.; Danner, R. P. Improved Equation for Prediction of Saturated Liquid Densit. J. Chem. Eng. Data 1972, 17, 236-241.

(22) TRC Tables, Selected values of properties of chemical compounds: Thermodynamics Research Center Data Project; Texas A\&M University: College Station, 1972; Vol. 1.

(23) Kumagai, A.; Iwasaki, H. Pressure-volume-temperature relationships of $\mathrm{CH}_{3} \mathrm{COOC}_{2} \mathrm{H}_{5}$ and generalized Tait equation for liquids at high pressures. J. Chem. Eng. Data 1979, 24, 261-263.

(24) Zábranský, M.; Rùička, V.; Majer, V.; Domalski, E. S. Heat capacity of liquids: Volume II. Critical review and recommended values. $J$. Phys. Chem. Ref. Data, Monograph No. 6, 1996.

Received for review April 11, 2008. Accepted April 29, 2008.

JE800251V 